\title{
Sensitivity to change and responsiveness of lowering to the ground and rising from the ground evaluation in Duchenne muscular dystrophy: one-year longitudinal observation
}

\author{
RENATA ESCORCIO ${ }^{1}$ | MARIANA C. VOOS² | JOYCE MARTINI ${ }^{3}$ | MARIENE S. SIMÕES ${ }^{4}$ | FÁTIMA A. CAROMANO5
}

${ }_{1}^{1}$ PhD student, Medicine School of University of São Paulo (USP), Physiotherapy and Behavior Laboratory, São Paulo, SP, Brazil.

${ }^{2} \mathrm{PhD}$ Researcher at Medicine School of University of São Paulo (USP), Physiotherapy and Behavior Laboratory. Professor Doctor at Ibirapuera University, São Paulo, SP,

Brazil.

${ }^{3}$ Master in Rehabilitation Sciences, Medicine School of University of São Paulo (USP), Physiotherapy and Behavior Laboratory, São Paulo, SP, Brazil.

${ }^{4}$ Master student, Medicine School of University of São Paulo (USP), Physiotherapy and Behavior Laboratory, São Paulo, SP, Brazil.

${ }_{5}^{5}$ Professor Doctor, Medicine School of University of São Paulo (USP), Physiotherapy and Behavior Laboratory, São Paulo, SP, Brazil.

Correspondence to: Renata Escorcio. Avenida Presidente João Goulart, 04 - Ed. Pensilvânia, 48. Cep 06036-048, São Paulo-SP, Brasil.

email: reescorcio@hotmail.com

https://doi.org/10.20338/bjmb.v15i3.233

\begin{abstract}
HIGHLIGHTS
- Lowering to rising from the ground in patients with Duchenne muscular dystrophy.

- Three months intervals changes lowering to

the ground and rising from the ground.

- Six to twelve months intervals changes

became more apparent.

- Patients should be reassessed after nine months from the lowering to and rising from the ground.
\end{abstract}

$\begin{array}{ll}\text { ABBREVIATIONS } \\ \text { Cl } & \text { Confidence interval } \\ \text { DMD } & \text { Duchenne muscular dystrophy } \\ \text { ES } & \text { Effect sizes } \\ \text { FES } & \text { Functional Evaluation Scale } \\ \text { ICC } & \text { Intraclass coefficients } \\ \text { MCID } & \text { Minimal clinically important } \\ & \text { differences } \\ \text { MDC } & \text { Minimal detectable changes } \\ \text { MFM } & \text { Motor Function Measure } \\ \text { NSAA } & \text { North Star Ambulatory } \\ & \text { Assessment } \\ \text { SD } & \text { Standard deviation } \\ \text { SRM } & \text { Standardized response means }\end{array}$

PUBLICATION DATA

Received 26022021

Accepted 28082021

Published 01092021
BACKGROUND: The progressive weakness of Duchenne muscular dystrophy (DMD) interferes with performance. This study investigated the sensitivity to change and the responsiveness of sitting and standing from the ground in patients with DMD.

AIM: The aim was to assess the sensitivity to change and the responsiveness of lowering to/ rising from the ground, in three, six, nine, and twelve month-evaluation intervals and to define the most suitable reevaluation intervals for ambulatory patients with DMD.

METHOD: This is an observational, longitudinal study. Recordings of 28 patients performing lowering to/ rising from the ground were analyzed. Sensitivity to change was assessed using effect sizes and standardized response means. Responsiveness was assessed using minimal detectable changes (MDC) and minimal clinically important differences (MCID).

RESULTS: In the lowering to the ground, significant sensitivity to change was found in higher than 6 months reassessment intervals. In the rising from the ground, significant sensitivity to change was observed in higher than 9 reassessment intervals. MDC and MCID varied from 1.0 to 1.6 points and from 0.5 to 2.5 seconds when lowering to the ground and from 1.3 to 2.6 points and from 5.0 to 28.0 seconds when rising from the ground. CONCLUSION: Patients should be reassessed after nine months from the lowering to and rising from the ground. Increments of 2.0 points and/or 2.5 seconds (or higher) in the score of lowering to the ground assessment denote clinically relevant changes. Increments of 3 points (or higher) in rising from the ground assessment are clinically relevant. In this task, the timed performance showed high variability and should be analyzed in association with other measures for clinical decision-making.

KEYWORDS: Evaluation | Neuromuscular diseases | Outcome assessment | Psychometrics

\section{INTRODUCTION}

The progressive muscle weakness that occurs in Duchenne muscular dystrophy (DMD) impairs functional performance..$^{1-5}$ Considering the increase in life expectancy $4,6,7$ and the new treatment techniques 8,9 in DMD, assessment tools must express the functional and clinical status of patients with DMD accurately. Functional assessment is essential to describe DMD progression, which can be measured by scales with determined sensitivity to change and responsiveness. ${ }^{10-14}$ 
Sensitivity to change and responsiveness analyses specify reassessment time intervals ${ }^{10-13}$ and indicate the magnitude of the changes related to natural progression [15] or treatment. ${ }^{16}$ The sensitivity to change and the responsiveness of the Motor Function Measure (MFM), ${ }^{12}$ the North Star Ambulatory Assessment (NSAA) ${ }^{7}$ and questionnaire ACTIVLIM ${ }^{11}$ have been described. However, these instruments are time-consuming and require specific standardized equipment.

The evaluation of lowering to the ground and rising from the ground is simple, fast, and requires few spaces and equipment. These activities can be performed in any regular examination room and filmed (after proper consent is given by children and caregivers). The films can be scored by the Functional Evaluation Scale for patients with DMD (Table 1). The test assesses specific compensatory movements of lowering to the ground and rising from the ground in ambulatory patients with DMD. ${ }^{17}$ The timed performance can be measured digitally with any regular film-watching software or with a chronometer.

The Gowers sign is one of the most important clinical characteristics of boys with DMD. It was described by the neurologist Sir William Richard Gowers, as a pattern of rising from the floor, from a supine or sitting position, which is seen in boys with pseudo hypertrophic muscular paralysis. ${ }^{18} \mathrm{It}$ is a clinical sign for how children with DMD rise from the ground by grasping and pulling on body parts from the knees to hips. The use of arms and hands is observed firstly to roll prone, then to extend arms and legs and "climb up the thighs" to assuming an erect posture. ${ }^{19}$ These compensatory movements are indicative of proximal muscle weakness, involving the pelvic girdle and lower extremities.3,17,20,21

Although not formally observed in clinical practice, lowering to the ground may also provide relevant information. As the child will have to assume the supine position before rising from the ground, clinicians and researchers may ask the child to perform this task as independently as possible and record the lowering to the ground task. This combined assessment will not add extra evaluation time. Besides, observing the way the child exerts eccentric control with antigravity postural muscles will provide information about the compensatory movements performed and the time required. ${ }^{21}$

Sitting and standing from the ground are frequently used in research and clinical practice to evaluate patients with DMD. These tasks can evidence how much antigravity muscles are affected. However, the sensitivity to change and the responsiveness of sitting and standing from the ground are not clear. Therefore, reassessments can be scheduled in intervals that may lack some changes or are not long enough to detect them.

This study investigated the sensitivity to change and the responsiveness of sitting and standing from the ground in patients with DMD. The aim was to assess the sensitivity to change and the responsiveness of lowering to/ rising from the ground, in three, six, nine, and twelve months-evaluation intervals and to define the most suitable reevaluation intervals for ambulatory patients with DMD. 
Brazilian Journal of Motor Behavior

Table 1 - Functional Evaluation Scale for compensatory movements scoring in DMD

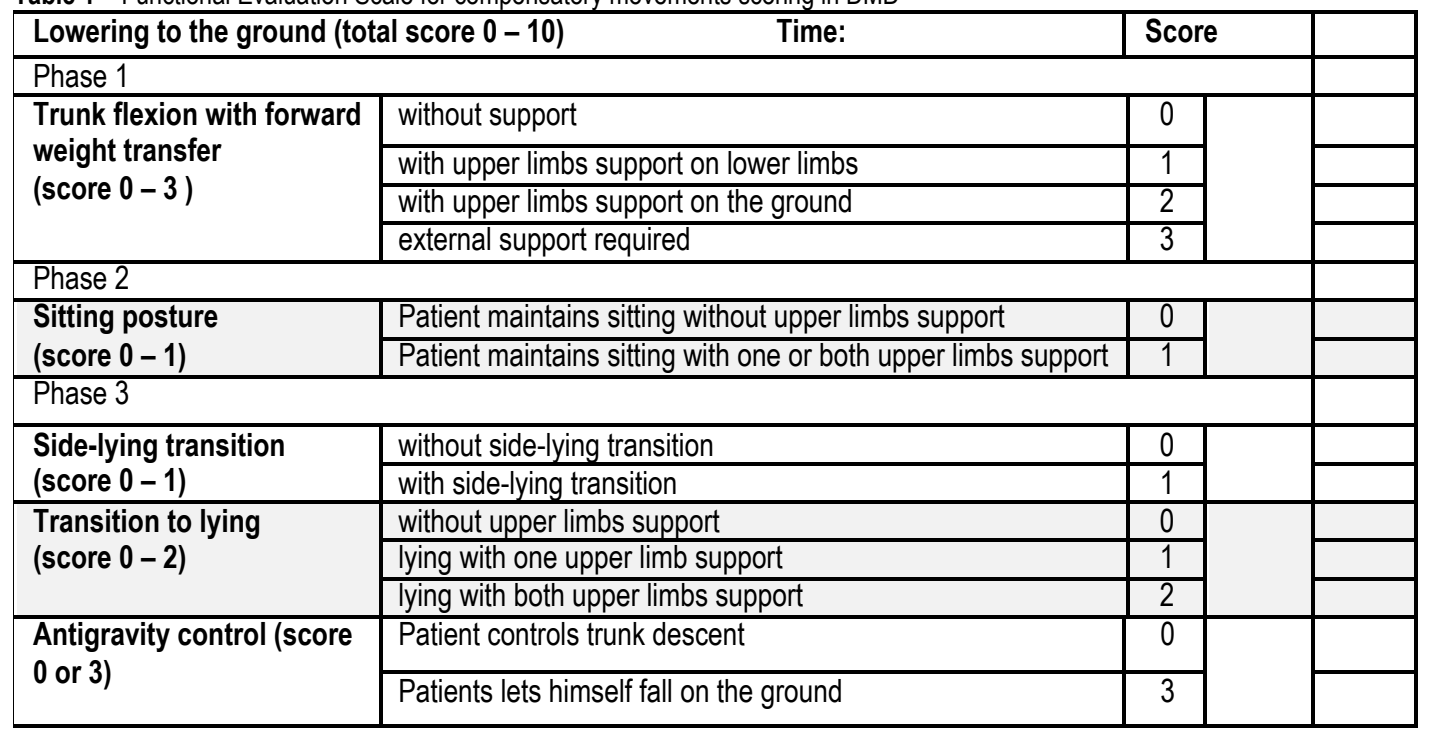

\begin{tabular}{|c|c|c|}
\hline \multicolumn{2}{|c|}{ Rising from the ground (total score $0-15$ ) } & Score \\
\hline \multicolumn{3}{|c|}{ Phase 1} \\
\hline \multirow{3}{*}{$\begin{array}{l}\text { Supine to sitting } \\
(\text { score } 0-2)\end{array}$} & without upper limb support & 0 \\
\hline & with one upper limb support & 1 \\
\hline & with both upper limbs support & 2 \\
\hline \multicolumn{3}{|l|}{ Phase 2} \\
\hline \multirow{2}{*}{$\begin{array}{l}\text { Side-lying transition } \\
\text { (score } 0 \text { or } 2 \text { ) }\end{array}$} & without side-lying transition & 0 \\
\hline & with side-lying transition & 2 \\
\hline \multirow{4}{*}{$\begin{array}{l}\text { Sitting posture } \\
(\text { score } 0-3)\end{array}$} & Patient does not perform transition to sitting & 0 \\
\hline & Patient maintains sitting without upper limbs support & 1 \\
\hline & Patient maintains sitting with one upper limb support & 2 \\
\hline & Patient maintains sitting with both upper limbs support & 3 \\
\hline \multicolumn{3}{|c|}{ 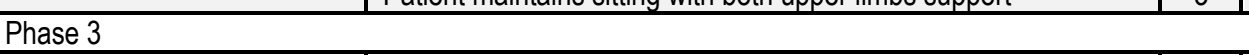 } \\
\hline \multirow{2}{*}{$\begin{array}{l}\text { Sitting to quadrupedalism } \\
\text { (score } 0-1)\end{array}$} & Patient does not perform quadrupedalism & 0 \\
\hline & external support required & 1 \\
\hline \multicolumn{3}{|l|}{ Phase 4} \\
\hline \multirow{3}{*}{$\begin{array}{l}\text { Quadrupedalism to } \\
\text { kneeling and/or half- } \\
\text { kneeling (score } 0-2 \text { ) }\end{array}$} & $\begin{array}{l}\text { Patient does not perform kneeling and/or half-kneeling before } \\
\text { standing }\end{array}$ & 0 \\
\hline & Patient performs transition to kneeling or half-kneeling & 1 \\
\hline & Patient performs transitions to kneeling and half-kneeling & 2 \\
\hline \multicolumn{3}{|l|}{ Phase 5} \\
\hline \multirow{5}{*}{$\begin{array}{l}\text { Transition to } \\
\text { standing (score } 0-4 \text { ) }\end{array}$} & upper limbs support on lower limbs is not necessary & 0 \\
\hline & upper limb support on the knee & 1 \\
\hline & upper limbs support on the knees and thighs & 2 \\
\hline & upper limbs support on legs, knees and thighs & 3 \\
\hline & external support required & 4 \\
\hline \multirow[t]{2}{*}{ Standing (score 0 - 1) } & Patient can stand without support & 0 \\
\hline & Patient cannot stand without support & 1 \\
\hline
\end{tabular}

\section{METHODS}

This is an observational and longitudinal study approved by the Research Ethics Committee of Faculty of Medicine of the University of São Paulo, process 435/13. 


\section{Subjects}

Recordings of 36 boys (with molecular DMD diagnosis) from the Laboratory of Physiotherapy and Behavior were analyzed. All of them had been diagnosed at least two years before this study. Children were evaluated at three months intervals within one year (five assessments per child). Participants with missing reassessment data were excluded $(n=8)$. Thus, we evaluated 140 recordings of lowering to the ground (5 evaluations per child) and 140 recordings of rising from the ground ( 5 evaluations per child) of 28 boys with DMD (Figure 1).

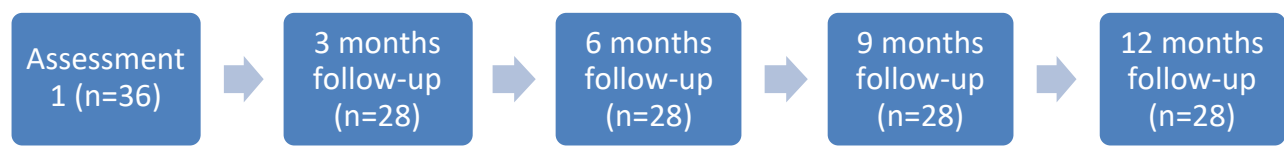

Figure 1. Assessment protocol. Legend: $n=36$ : firstly, recordings of 36 boys were observed. However, due to missing data, 8 were excluded. Therefore, 28 were reassessed after $3,6,9$, and 12 months.

Considering that we had a convenience sample, we calculated the sample size according to the confidence level of $95 \%$, the total width of our confidence interval $(\mathrm{Cl}=10)$, and the mean standard deviation $(S D=2)$ and we found that our final sample size $(n=28)$ was valid. ${ }^{22,23}$ As we started with a sample of 36 and finished with a sample of 28 boys, the follow-up rate was $78 \%$.

All participating children were ambulatory. Boys were filmed in sagittal and frontal planes. ${ }^{17}$ Scoring from 1 to 3 on Vignos scale ${ }^{24}$ at the first evaluation was adopted as the inclusion criterion. Sample characteristics are presented in table 2 (Table 2).

Table 2 - Sample characteristics

\begin{tabular}{|c|c|c|c|}
\hline Characteristics & Age & Weight & Heigh \\
\hline Mean & 7.8 years & 40.1 kilograms & 1.35 meters \\
\hline Standard deviation & 1.9 years & 9.9 kilograms & 0.14 meters \\
\hline
\end{tabular}

\section{Procedure}

The Functional Evaluation Scale for patients with DMD assesses specific compensatory movements of ambulatory patients. Previous studies showed inter-and intra-observer reliability of compensatory movements scoring. $5,14,17,20,21$ The domain lowering to the ground and rising from the ground showed excellent intra and inter reliability. ${ }^{17}$ The maximum score of lowering to the ground is 10 and the maximum score of rising from the ground is 15 . Higher scores denote more compensatory movements, therefore, poorer clinical and functional status (Table 1).

Simple verbal commands were given, explaining that volunteers should perform the tasks as fast as possible. The time for lowering to the ground was measured from the moment the child was able to keep the orthostatic position up to lying on the ground. The time spent standing up from the ground was measured in seconds from the moment the child was in dorsal decumbent position until acquiring the upright position. Three collections were made, and the mean score and timed performance were used. The tasks were filmed in sagittal and frontal planes.

To facilitate data collection and analysis, FES-DMD-DATA software was used. ${ }^{25}$ FES-DMD-DATA displayed the video on one side of the computer screen and the scoring sheet on the other side. The rater could then watch the video and score the compensatory 
movements simultaneously. The video could be watched in slow motion and repeated or paused whenever necessary.

Five assessments were carried out in the period of one year, with three months intervals. Two raters filmed the patients and another one scored the compensatory movements and time. All examiners had a minimum of two years of experience with patients with neuromuscular disorders. Patients were scored randomly, and the rater was blinded to the previous scores given to the same and other patients and demographic data (age, Vignos, height, weight).

To assess the sensitivity to change, reevaluation periods of three months $(0$ to 3,3 to 6,6 to 9 , and 9 to 12 months), six months (0 to 6, 3 to 9,6 to 12), nine months (0 to 9 and 3 to 12 months) and one year (0 to 12 months) were adopted.

\section{Statistical Analysis}

According to the COSMIN taxonomy, measurement properties of outcome measurement instruments include reliability, responsiveness, validity, and interpretability. Reliability involves test-retest, inter-rater and intra-rater measures, internal consistency, and measurement error, that were previously described for FES-DMD.5,14,17,20,21 Responsiveness, which is approached in the present study, refers to the ability of an outcome measure to detect change over time in the construct to be measured. It refers to the validity of a change score, and it is distinguished from validity in the taxonomy for reasons of clarity. Further studies should investigate interpretability and validity, which involves content validity, construct validity, and criterion validity. Sensitivity to change was determined by the effect size (ES) and the standardized response mean (SRM) calculations. For quantifying and interpreting the sensitivity to change over time, the combined use of ES and SRM is recommended. ${ }^{26-29}$ To calculate the ES, the equation: ES $=\left(M_{x}-M_{0} / S D_{0}\right)$ was used. $M x$ was the mean score of the assessment $x . M_{0}$ was the mean score of the initial evaluation and $\mathrm{SD}_{0}$ was the standard deviation of the initial evaluation. $S R M$ was defined as $S R M=\left(M_{x}-M_{0} / S D_{M x-M O}\right)$, in which the difference between $M_{x}$ and $M_{0}$ was divided by the standard deviation of the difference between $M_{x}$ and $M_{0}{ }^{26}$

We calculated our ES and SRM significance levels based on the confidence level of $95 \%$, the mean width of the confidence level of 10 , the standard deviation of 2 , the sample size of $28, \alpha=0.05$, and $\beta=0.20 .{ }^{22}$ Therefore, significant effect sizes were determined as $\geq 0.70$.

Responsiveness was determined by the minimal detectable change (MDC) and the minimal clinically important difference (MCID). ${ }^{30}$ The response capacity over time was calculated by the MDC and the MCID. The MDC was calculated by the equation $1.96 \sqrt{2}[\mathrm{SD} \sqrt{ }(1-\mathrm{ICC})]$. The intraclass coefficients (ICC) calculated in our previous study ${ }^{17}$ were used (lowering to the ground: 0.93; rising from the ground: 0.92). The MCID is the smallest clinical change a patient would identify as important. It was determined using the one-half standard deviation benchmark of each measure. ${ }^{30}$

\section{RESULTS}

The demographic data and the scores of lowering to the ground and rising from the ground are displayed in Table 2. The minimum and maximum scores and times, and the responsiveness measures (MDC and MCID) are shown in Table 3 . The sensitivity to 
Brazilian Journal of Motor Behavior

change measures (ES and SRM) are displayed in Table 4.

In the lowering to the ground scores and timed performance, significant sensitivity to change was found in 6 (or higher) reassessment intervals. In the rising from the ground, significant sensitivity to change was observed in 6 (or higher) reassessment intervals for scores and in 9 (or higher) intervals for timed performance (ES and SRM significance levels set as $\geq 0.70$ ). MDC and MCID varied from 1.0 to 1.6 points and from 0.5 to 2.5 seconds in the lowering to the ground and from 1.3 to 2.6 points and from 5.0 to 28.0 seconds in the rising from the ground.

Table 3 - Scores and times on lowering to the ground and rising from the ground.

\begin{tabular}{|c|c|c|c|c|c|c|c|c|c|c|c|c|c|}
\hline \multirow[t]{2}{*}{ Activity } & \multirow[t]{2}{*}{ Measure } & \multirow[t]{2}{*}{$\begin{array}{c}\text { Age } \\
\text { (years) }\end{array}$} & \multirow[t]{2}{*}{$\begin{array}{l}\text { Vignos } \\
\text { (score) }\end{array}$} & \multicolumn{2}{|c|}{$\begin{array}{l}\text { Assessment } 1 \\
\text { (initial) }\end{array}$} & \multicolumn{2}{|c|}{$\begin{array}{l}\text { Assessment } 2 \\
\text { (after } 3 \text { months) }\end{array}$} & \multicolumn{2}{|c|}{$\begin{array}{l}\text { Assessment } 3 \\
\text { (after } 6 \text { months) }\end{array}$} & \multicolumn{2}{|c|}{$\begin{array}{l}\text { Assessment } 4 \\
\text { (after } 9 \text { months) }\end{array}$} & \multicolumn{2}{|c|}{$\begin{array}{c}\text { Assessment } 5 \\
\text { (after } 12 \text { months) }\end{array}$} \\
\hline & & & & Score & $\begin{array}{l}\text { Time } \\
(\mathrm{mS})\end{array}$ & Score & $\begin{array}{l}\text { Time } \\
(\mathrm{mS})\end{array}$ & Score & $\begin{array}{l}\text { Time } \\
(\mathrm{mS})\end{array}$ & Score & $\begin{array}{l}\text { Time } \\
(\mathrm{mS})\end{array}$ & Score & $\begin{array}{l}\text { Time } \\
(\mathrm{mS})\end{array}$ \\
\hline \multirow{7}{*}{$\begin{array}{l}\text { Lowering to } \\
\text { the ground }\end{array}$} & Minimum & 5.0 & 1.0 & 0.0 & 1320.0 & 0.0 & 1380.0 & 0.0 & 1220.0 & 1.0 & 1170.0 & 1.0 & 1080.0 \\
\hline & $25^{\text {th }}$ percentile & 6.3 & 1.0 & 2.0 & 2087.5 & 2.5 & 2017.5 & 4.0 & 2167.5 & 4.0 & 2622.5 & 5.0 & 2567.5 \\
\hline & $50^{\text {th }}$ percentile & 8.0 & 2.0 & 4.5 & 2330.0 & 5.0 & 2605.0 & 5.0 & 2855.0 & 5.0 & 3615.0 & 5.5 & 3100.0 \\
\hline & $75^{\text {th }}$ percentile & 9.0 & 3.0 & 5.0 & 2840.0 & 5.0 & 3242.5 & 5.8 & 3922.5 & 7.0 & 4737.5 & 7.0 & 6947.5 \\
\hline & Maximum & 12.0 & 3.0 & 7.0 & 6290.0 & 8.0 & 7380.0 & 8.0 & 11880.0 & 8.0 & 12010.0 & 8.0 & 12110.0 \\
\hline & $\begin{array}{c}\text { Minimal } \\
\text { detectable } \\
\text { change (MDC) } \\
\end{array}$ & 1.4 & 0.6 & 1.6 & 764.6 & 1.6 & 1038.9 & 1.5 & 2022.3 & 1.6 & 2269.2 & 1.5 & 2516.8 \\
\hline & $\begin{array}{c}\begin{array}{c}\text { Minimal clinically } \\
\text { important } \\
\text { difference (MCID) }\end{array} \\
\end{array}$ & 0.9 & 0.4 & 1.1 & 510.9 & 1.0 & 694.1 & 1.0 & 1351.2 & 1.1 & 1516.2 & 1.0 & 1681.6 \\
\hline \multirow{7}{*}{$\begin{array}{l}\text { Rising from } \\
\text { the ground }\end{array}$} & Minimum & 5.0 & 1.0 & 3.0 & 3520.0 & 4.0 & 4830.0 & 4.0 & 4930.0 & 4.0 & 4990.0 & 4.0 & 5020.0 \\
\hline & $25^{\text {th }}$ percentile & 6.3 & 1.0 & 4.0 & 8192.5 & 5.0 & 7545.0 & 5.0 & 7475.0 & 6.0 & 7915.0 & 7.0 & 8312.5 \\
\hline & $50^{\text {th }}$ percentile & 8.0 & 2.0 & 6.5 & 13140.0 & 7.5 & 19245.0 & 9.0 & 17005.0 & 9.0 & 19380.0 & 9.5 & 22840.0 \\
\hline & $75^{\text {th }}$ percentile & 9.0 & 3.0 & 8.8 & 28215.0 & 9.8 & 34650.0 & 11.0 & 33112.5 & 13.0 & 36927.5 & 13.0 & 44347.5 \\
\hline & Maximum & 12.0 & 3.0 & 12.0 & 37980.0 & 13.0 & 55070.0 & 13.0 & 81600.0 & 14.0 & 100080.0 & 14.0 & 127200.0 \\
\hline & $\begin{array}{c}\text { Minimal } \\
\text { detectable } \\
\text { change (MDC) }\end{array}$ & 1.4 & 0.6 & 2.0 & 9420.0 & 2.3 & 12287.0 & 2.6 & 17312.9 & 2.6 & 20282.2 & 2.5 & 28811.5 \\
\hline & $\begin{array}{l}\text { Minimal clinically } \\
\text { important } \\
\text { difference (MCID) }\end{array}$ & 0.9 & 0.4 & 1.3 & 5887.5 & 1.5 & 7679.4 & 1.6 & 10820.6 & 1.6 & 12676.4 & 1.6 & 18007.2 \\
\hline
\end{tabular}


Brazilian Journal of Motor Behavior

Table 4 - Sensitivity to change of lowering to the ground in reevaluation periods of three, six, nine and twelve months.

\begin{tabular}{|c|c|c|c|c|c|c|c|c|c|c|c|}
\hline \multicolumn{2}{|c|}{ Reevaluation interval } & \multicolumn{4}{|c|}{3 months } & \multicolumn{3}{|c|}{6 months } & \multicolumn{2}{|c|}{9 months } & 12 months \\
\hline Activity (scores) & Measure & $0-3 \mathrm{mo}$ & 3-6 mo & 6-9 mo & 9-12 mo & $0-6 \mathrm{mo}$ & $3-9 \mathrm{mo}$ & 6-12 mo & $0-9 \mathrm{mo}$ & 3-12 mo & $0-12 \mathrm{mo}$ \\
\hline \multirow{2}{*}{$\begin{array}{l}\text { Lowering to the } \\
\text { ground score }\end{array}$} & Effect size (ES) & 0.28 & 0.23 & 0.28 & 0.20 & 0.50 & 0.50 & 0.48 & $0.77^{*}$ & $0.70^{*}$ & $0.96^{*}$ \\
\hline & $\begin{array}{c}\text { Standardized } \\
\text { Response Mean } \\
\text { (SRM) }\end{array}$ & 0.55 & 0.57 & 0.62 & 0.43 & $0.75^{\star}$ & $0.99^{*}$ & $0.77^{*}$ & $1.05^{*}$ & $1.02^{*}$ & $1.15^{\star}$ \\
\hline \multirow{2}{*}{$\begin{array}{l}\text { Rising from the } \\
\text { ground score }\end{array}$} & Effect size (ES) & 0.40 & 0.32 & 0.29 & 0.28 & 0.68 & 0.53 & 0.52 & $0.92^{*}$ & $0.71^{*}$ & $1.19^{*}$ \\
\hline & $\begin{array}{c}\text { Standardized } \\
\text { Response Mean } \\
\text { (SRM) }\end{array}$ & 0.55 & 0.68 & 0.63 & 0.66 & $0.73^{*}$ & $0.97^{*}$ & $0.96^{*}$ & $1.03^{*}$ & $1.12^{*}$ & $1.25^{*}$ \\
\hline Activity (times) & Measure & $0-3 \mathrm{mo}$ & 3-6 mo & 6-9 mo & 9-12 mo & $0-6 \mathrm{mo}$ & 3-9 mo & 6-12 mo & $0-9 \mathrm{mo}$ & 3-12 mo & $0-12 \mathrm{mo}$ \\
\hline \multirow{2}{*}{$\begin{array}{l}\text { Lowering to the } \\
\text { ground timed } \\
\text { performance }\end{array}$} & Effect size (ES) & 0.42 & 0.55 & 0.28 & 0.18 & $1.17^{*}$ & $1.09^{*}$ & 0.57 & $1.90^{*}$ & $1.27^{*}$ & $2.14^{*}$ \\
\hline & $\begin{array}{c}\text { Standardized } \\
\text { Response Mean } \\
\text { (SRM) }\end{array}$ & 0.40 & 0.36 & 0.30 & 0.17 & 0.51 & 0.62 & 0.44 & $0.71^{*}$ & $0.70^{*}$ & $0.73^{*}$ \\
\hline \multirow{2}{*}{$\begin{array}{l}\text { Rising from the } \\
\text { ground timed } \\
\text { performance }\end{array}$} & Effect size (ES) & 0.40 & 0.26 & 0.16 & 0.33 & 0.66 & 0.42 & 0.54 & $0.94^{*}$ & $0.96^{*}$ & $1.64^{*}$ \\
\hline & $\begin{array}{c}\text { Standardized } \\
\text { Response Mean } \\
\text { (SRM) }\end{array}$ & 0.47 & 0.27 & 0.21 & 0.49 & 0.21 & 0.36 & 0.46 & 0.65 & 0.68 & $0.71^{*}$ \\
\hline
\end{tabular}

*Significance level for the effect size and standardized response mean was determined as $\geq 0.70$. This calculation was based on the confidence level of $95 \%$, the mean width of confidence level of 10 , standard deviation of 2 , sample

\section{DISCUSSION}

The present study investigated the sensitivity to change and the responsiveness of sitting and standing from the ground in patients with DMD. The aim was to assess the sensitivity to change and the responsiveness of lowering to/ rising from the ground, in three, six, nine, and twelve months-evaluation intervals and to define the most suitable reevaluation intervals for ambulatory patients with DMD. Our results showed that, in three months evaluation intervals, it was possible to observe functional changes in lowering to the ground and rising from the ground. However, these changes became more apparent and reached a significant level in longer reevaluation periods (in six to twelve months intervals).

With the progression of DMD, there was a need to employ compensatory movements to perform lowering to and rising from the ground. ${ }^{17,20,21}$ The observation of upper limb support on the ground during trunk flexion and side-lying, corroborates with the previous studies by Martini, Voos, Hukuda, Resende, \& Caromano (2014)20 and Martini, Hukuda, Caromano, Favero, Fu \& Voos (2015) ${ }^{21}$. These compensatory movements were performed to compensate for the progressive loss of eccentric and antigravity control during the transition from standing to sitting. Significant variation was observed among children, which was expected, due to genetic and environmental heterogeneity. ${ }^{4}$

The most frequently observed compensatory movement occurred during the transition from quadrupedalism to standing, with a frequent need for external support. This can be explained by factors such as difficulty contracting hip and trunk extensor muscles, 
difficulty maintaining semi-kneeling posture due to hip flexor muscles weakness, and difficulty performing hip, knee, and ankle extensions in a closed kinetic chain.20,21 Compensatory movements observed during rising from the ground are a typical way of dealing with the weakness of lower limb muscles, which work against the gravity force.

Mazzone et al. (2013) ${ }^{7}$ investigated functional impairments and possible indicators of gait loss in boys with DMD in 24 months. They assessed rising from the ground by timed performance, which was considered a biomarker of DMD progression. They found that the number of boys who did not carry out the activity progressively increased at 12 and 24 months. The inability of rising from the ground was followed by gait interruption. The present study detected clinical changes in rising from the ground since three months intervals (even with a much smaller sample). Most children of our study showed significant clinical changes after six months. This shows that in research and clinical practice, reevaluation intervals of six months can be used for rising from the ground assessment.

Not only rising from the ground but also lowering to the ground is relevant in DMD evaluation and clinical decision making. 17,20,21 In some psychometric properties, lowering to the ground testing was even more responsive than rising from the ground. In lowering to the ground scores and timed performance, significant sensitivity to change was found in 6 (or higher) reassessment intervals. In rising from the ground, significant sensitivity to change was observed in 6 (or higher) reassessment intervals for scores and in 9 (or higher) intervals for timed performance. MDC and MCID varied from 1.0 to 1.6 points and from 0.5 to 2.5 seconds in lowering to the ground and from 1.3 to 2.6 points and from 5.0 to 28.0 seconds in rising from the ground. This lower variability in lowering to the ground scores and mainly in timed performance facilitates clinical decision making based on ES, SRM, MDC, and MCID.

Vuillerot et al. (2013)12 investigated the sensitivity to change of MFM in boys with DMD (10 ambulatory and 31 wheelchair-dependent). They found high sensitivity to change with $S R M=0.91$ after one year. Vandervelde et al. (2009) ${ }^{11}$ investigated the sensitivity to change of ACTIVLIM questionnaire, which evaluates the limitations in daily activities in patients with neuromuscular diseases. Twenty-seven boys with DMD were evaluated in two sessions with an interval of $21 \pm 4$ months (11-27 months). The questionnaire showed $\mathrm{SRM}=0.81$. We believe that lowering to and rising from the ground can be used as a complementary assessment. These activities can detect clinical changes in shorter intervals than MFM and ACTIVLIM and may provide additional information to these wellknown testing protocols.

Lowering to the ground and rising from the ground assessments are simple, inexpensive, change sensitive, and reliable. They can be used to detect and follow not only DMD but also other neuromuscular disorders., ${ }^{3,17}$ The recording of lowering to the ground and rising from the ground provides permanent and standardized records of compensatory movements and timed performance. Therefore, these tasks can be used for clinical and research purposes to describe and compare patients and groups.

\section{Study limitations}

Considering that our follow-up rate was 78\% (which must be considered as a limitation) and that age and Vignos scores are related to FES and time variability, future studies should assess larger samples. Multicentric studies can investigate potential differences in sensitivity to change and responsiveness with age and Vignos levels stratification. 


\section{CONCLUSION}

Patients should be assessed in six months or longer intervals in lowering to the ground and in nine months or longer intervals in rising from the ground. Increments of 2.0 points and/or 2.5 seconds (or higher) in the score of lowering to the ground assessment denote clinically relevant changes. Increments of 3 points (or higher) in rising from the ground assessment are clinically relevant. In this task, the timed performance showed high variability and should be analyzed in association with other measures for clinical decisionmaking.

\section{REFERENCES}

1. Steffensen BF, Lyager S, Werge B, Rahbek J, Mattsson E. Physical capacity in nonambulatory people with Duchenne muscular dystrophy or spinal muscular atrophy: a longitudinal study. DMCN. 2002; 44:623-632.

2. Uchikawa K, Liu M, Hanayama K, Tsuji T, Fujiwara T, Chino N. Functional status and muscle strength in people with Duchenne muscular dystrophy living in the community. Journal of Rehabilitation Medicine. 2004; 36:124-129.

3. Chang RF, Mubarak SJ. Pathomechanics of Gowers' Sign: A Video Analysis of a Spectrum of Gowers' Maneuvers. Clinical Orthopaedics and Related Research. 2012; 470: 1987-1991.

4. Humbertclaude V, Hamroun D, Bezzou K, Bérard C, Boespflug-Tanguy O, Bommelaer C, et al. Motor and respiratory heterogeneity in Duchenne patients: Implication for clinical trials. European Journal of Paediatric Neurology. 2012; 16:149-160.

5. Carvalho EV, Hukuda ME, Escorcio R, Voos MC, Caromano FA. Development and reliability of the functional evaluation scale for Duchenne muscular dystrophy, Gait domain: a pilot study. Physiotherapy Research International. 2015; 20:135-146.

6. Jung YI, Chae JH, Park SK, Kim JH, Kim JY, Kim SJ, et al. The Correlation Analysis of Functional Factors and Age with Duchenne Muscular Dystrophy. Annals of Rehabilitation Medicine. 2012; 36:22-32.

7. Mazzone ES, Pane M, Sormani MP, Scalise R, Berardinelli A, Messina S, et al. 24 Month Longitudinal Data in Ambulant Boys with Duchenne Muscular Dystrophy. PlosOne. 2013; 8:1-6.

8. Niks E, Aartsma-Rus A. Exon skipping: a first in class strategy for Duchenne muscular dystrophy. Expert Opinion on Biological Therapy. 2016; In press

9. Dowling JJ. Eteplirsen therapy for Duchenne muscular dystrophy: skipping to the front of the line. Nature Reviews. Neurology. 2016; 12:675-676.

10. Scott E, Mawson SJ. Measurement in DMD: considerations in the development of a neuromuscular assessment tool. Developmental Medicine Child Neurology. 2006; 48:540544. 
11. Vandervelde L, Van den Bergh PYK, Goemans N, Thonnard JL. Activity limitations in patients with neuromuscular disorders: a responsiveness study of the ACTIVLIM questionnaire. Neuromuscular Disorders. 2009; 19:99-103.

12. Vuillerot C, Payan C, Girardot F, Fermanian J, Iwaz J, Bérard C, et al. Responsiveness of the motor function measure in neuromuscular diseases. Archives Physical Medicine and Rehabilitation. 2012; 93:2251-2256.

13. Mayhew AG, Cano SJ, Scott E, Eagle M, Bushby K, Manzur A, et al. Detecting meaningful change using the North Star Ambulatory Assessment in Duchenne muscular dystrophy. Developmental Medicine Child Neurology. 2013; 55:1046-52.

14. Albuquerque PS, Caromano FA, Voos MC, Favero FM, Farcic TF. Technological tools for observational evaluation - the experience with the software for Functional Evaluation Scale for Duchenne Muscular Dystrophy - A pilot study software for observational evaluation. British Journal of Medicine and Medical Research. 2016; 16:1-7.

15. Baumstarck K, Butzkueven H, Fernandez O, Flachenecker P, Stecchi S, Idiman E, et al. Responsiveness of Multiple Sclerosis International Quality of Life questionnaire to disability change: a longitudinal study. Health and Quality of Life Outcomes. 2013; 11:127-129.

16. Stucki G, Daltroy L, Katz JN, Johannesson M, Liang MH. Interpretation of change scores in ordinal clinical scales and health status measures: the whole may not equal the sum of the parts. Journal of Clinical Epidemiology. 1996; 49:711- 717.

17. Escorcio R, Caromano FA, Hukuda ME, Fernandes LAY. Development of an evaluation scale for sitting and rising from the ground for children with Duchenne muscular dystrophy. Journal of Motor Behavior. 2011; 43:31-6.

18. Gowers WR. Clinical lecture on pseudo-hypertrophic muscular paralysis. Lancet. 1879; 2: 1-2, 37-39, 73-75, 113-116.

19. Pearce JM. Gowers' sign. Journal of Neurology Neurosurgery and Psychiatry. 2000;68:149-150.

20. Martini J, Hukuda ME, Caromano FA, Favero F, Fu C, Voos MC. The clinical relevance of timed motor performance in children with DMD. Physiotherapy: Theory and Practice. 2015; 31:173-81.

21. Martini J, Voos MC, Hukuda ME, Resende MBD, Caromano FA. Compensatory movements during functional activities in ambulatory children with Duchenne muscular dystrophy. Arquivos de Neuropsiquiatria. 2014; 72:5-11.

22. Hulley S, Cummings S, Browner W, Grady D, Newman T. Designing clinical research: an epidemiologic approach. 4th ed. Philadelphia, PA: Lippincott Williams \& Wilkins, 2013. Appendix 6D page 80.

23. Vuillerot C, Girardot F, Payan C, Fermanian J, Iwaz J, De Lattre C, et al. Monitoring changes and predicting loss of ambulation in Duchenne muscular dystrophy with the Motor Function Measure. Developmental Medicine \& Child Neurology. 2009; 52:60-65.

24. Vignos PJ, Spencer GE, Archibald KC. Management of progressive muscular dystrophy of childhood. Journal American of Medical Association. 1963; 2:103-110. 
Brazilian Journal of Motor Behavior

25. Albuquerque PS, Voos MC, Simões MS, Martini J, Monteiro CB, Caromano FA. Responsiveness of the domain climbing up and going down stairs of the Functional Evaluation scale for Duchenne Muscular Dystrophy: a one year follow-up. Brazilian Journal of Physical Therapy. 2016; 20:471-476.

26. Middel B, Sonderen von E. Statistical significant change versus relevant or important change in (quasi) experimental design: some conceptual and methodological problems in estimating magnitude of intervention-related change in health services research. International Journal of Integrated Care. 2002; 2:1-18.

27. De Groot IJ, Post MW, Van Heuveln T, Van Den Berg LH, Lindeman E. Measurement of decline of functioning in persons with amyotrophic lateral sclerosis: responsiveness and possible applications of the Functional Independence Measure, Barthel Index, Rehabilitation Activities Profile and Frenchay Activities Index. Amyotrophic Lateral Sclerosis. 2006; 7:167-172.

28. Mehrholz J, Wagner K, Rutte K, Meibner D, Pohl M. Predictive Validity and Responsiveness of the functional ambulation category in hemiparetic patients after stroke. Archives Physical Medicine Rehabilitation. 2007; 88:1314-9.

29. Schrag A, Spottke A, Quinn NP, Dodel R. Comparative responsiveness of Parkinson's disease scales to change over time. Movement Disorders. 2009; 24:813-818.

30. Pardasaney PK, Latham NK, Jette AM, Wagenaar RC, Ni P, Slavin MD, et al. Sensitivity to change and responsiveness of four balance measures for community-dwelling older adults. Physical Therapy. 2012; 92:388-397.

Citation: Escorcio R, Voos MC, Martini J, Simões MS, Caromano FA. (2021). Sensitivity to change and responsiveness of lowering to the ground and rising from the ground evaluation in Duchenne muscular dystrophy: oneyear longitudinal observation. Brazilian Journal of Motor Behavior, 15(3): 267-277.

Editors: Dr Fabio Augusto Barbieri - São Paulo State University (UNESP), Bauru, SP, Brazil; Dr José Angelo Barela São Paulo State University (UNESP), Rio Claro, SP, Brazil; Dr Natalia Madalena Rinaldi - Federal University of Espírito Santo (UFES), Vitória, ES, Brazil.

Copyright:@ 2021 Escorcio, Voos, Martini, Simões and Caromono and BJMB. This is an open-access article distributed under the terms of the Creative Commons Attribution-Non Commercial-No Derivatives 4.0 International License which permits unrestricted use, distribution, and reproduction in any medium, provided the original author and source are credited.

Funding: There was no funding for this study.

Competing interests: The authors have declared that no competing interests exist.

DOI: https://doi.org/10.20338/bjmb.v15i3.233 